\title{
A large-scale investigation into the role of classical HLA loci in multiple types of severe infections, with a focus on overlaps with autoimmune and mental disorders
}

Ron Nudel 1,2,3 D, Rosa Lundbye Allesøe $e^{2,3,4}$, Wesley K. Thompson ${ }^{1,2,5}$, Thomas Werge ${ }^{1,2,6}$, Simon Rasmussen ${ }^{4}$ and Michael E. Benros $2,3,7^{*}$ (1)

\begin{abstract}
Background: Infections are a major disease burden worldwide. While they are caused by external pathogens, host genetics also plays a part in susceptibility to infections. Past studies have reported diverse associations between human leukocyte antigen (HLA) alleles and infections, but many were limited by small sample sizes and/or focused on only one infection.

Methods: We performed an immunogenetic association study examining 13 categories of severe infection (bacterial, viral, central nervous system, gastrointestinal, genital, hepatitis, otitis, pregnancy-related, respiratory, sepsis, skin infection, urological and other infections), as well as a phenotype for having any infection, and seven classical HLA loci (HLA-A, B, C, DPB1, DQA1, DQB1 and DRB1). Additionally, we examined associations between infections and specific alleles highlighted in our previous studies of psychiatric disorders and autoimmune disease, as these conditions are known to be linked to infections.

Results: Associations between HLA loci and infections were generally not strong. Highlighted associations included associations between $\mathrm{DQB} 1{ }^{*} 0302$ and $\mathrm{DQB} 1{ }^{*} 0604$ and viral infections $(P=0.002835$ and $P=0.014332$, respectively), $\mathrm{DQB} 1{ }^{*} 0503$ and sepsis $(P=0.006053)$, and $\mathrm{DQA} 1{ }^{*} 0301$ with "Other" infections (a category which includes infections not included in our main categories e.g. protozoan infections) $(P=0.000369)$. Some HLA alleles implicated in autoimmune diseases showed association with susceptibility to infections, but the latter associations were generally weaker, or with opposite trends (in the case of HLA-C alleles, but not with alleles of HLA class II genes). HLA alleles associated with psychiatric disorders did not show association with susceptibility to infections.

Conclusions: Our results suggest that classical HLA alleles do not play a large role in the etiology of severe infections. The discordant association trends with autoimmune disease for some alleles could contribute to mechanistic theories of disease etiology.
\end{abstract}

Keywords: HLA, MHC, Association study, Immunogenetics, Infections, Autoimmune disease, Psychiatric disorder

*Correspondence: Michael.Eriksen.Benros@regionh.dk

2 iPSYCH, The Lundbeck Foundation Initiative for Integrative Psychiatric Research, Aarhus, Denmark

Full list of author information is available at the end of the article

\section{Background}

According to a World Health Organization report, infections are one of the major global burdens of disease [1], and they are a leading cause of early childhood mortality even today [2]. Not only can infections be deadly on their

(c) The Author(s) 2021. This article is licensed under a Creative Commons Attribution 4.0 International License, which permits use, sharing, adaptation, distribution and reproduction in any medium or format, as long as you give appropriate credit to the original author(s) and the source, provide a link to the Creative Commons licence, and indicate if changes were made. The images or other third party material in this article are included in the article's Creative Commons licence, unless indicated otherwise in a credit line to the material. If material is not included in the article's Creative Commons licence and your intended use is not permitted by statutory regulation or exceeds the permitted use, you will need to obtain permission directly from the copyright holder. To view a copy of this licence, visit http://creativeco mmons.org/licenses/by/4.0/. The Creative Commons Public Domain Dedication waiver (http://creativecommons.org/publicdomain/ zero/1.0/) applies to the data made available in this article, unless otherwise stated in a credit line to the data. 
own, but they often exacerbate existing conditions, often leading to fatal consequences [3, 4]. Given the above, studying the genetic basis of susceptibility to infection is of major importance in order both to identify individuals at high risk and also to gain a better understanding of the infection mechanism. At the time of writing this article, the global community is experiencing a pandemic caused by SARS-CoV-2; genetic studies (including ones examining the genes included in this study) are already providing useful information in the battle against the virus, but, especially when polymorphic loci are involved, the results illustrate the need for large-scale studies [5].

Some of the most important genetic loci that are involved in immune reaction are the classical human leukocyte antigen (HLA) genes, found in the human major histocompatibility complex (MHC) region on chromosome 6. Genes of HLA classes I and II are involved in antigen presentation to $T$ cells, whereby HLA class I genes encode proteins that present endogenous antigens to $\mathrm{CD}^{+} \mathrm{T}_{\mathrm{C}}$ (cytotoxic $\mathrm{T}$ ) cells and interact with natural killer (NK) cells, and HLA class II genes encode proteins that present exogenous antigens to $\mathrm{CD} 4^{+} \mathrm{T}_{\mathrm{H}}$ (T helper) cells [6]. Furthermore, some HLA genes are extremely polymorophic [7]. These two aspects of HLA genes made them popular candidates for investigations into susceptibility to infections of various kinds and in various populations, resulting in many reported associations [8, 9]. However, as noted by other authors [8], many of the reported HLA associations suffer from publication bias, and the studies reporting them often had small sample sizes. In parallel with investigations of HLA genes in the context of infections, HLA genes have also been studied in the contexts of autoimmune diseases [10] and psychiatric disorders such as schizophrenia [11]. Interestingly, both susceptibility to infection and autoimmune disorders have been linked to psychiatric disorders, both genetically and from an epidemiological perspective [12-14]. Our own previous studies have also examined associations between classical HLA alleles and psychiatric disorders [15], as well as overall autoimmune disease [13].

In this study we test for association between HLA loci and susceptibility to severe infections utilizing a large, genetically homogeneous Danish sample from the iPSYCH2012 study, which included register-based diagnoses for psychiatric disorders, infections and autoimmune diseases as well as genetic data. The aim of this study was twofold: firstly, we wanted to test for genetic association between HLA alleles and multiple infection categories representing severe infections (infections requiring hospitalization). In this regard, our sample size, which included more than 10,000 cases for some infection categories e.g. bacterial or viral infections, is a vast improvement compared to most of the previous studies. Secondly, we wanted to examine specific alleles highlighted in our previous studies of psychiatric disorders and autoimmune disease (namely, B*5701, C*0202, C*0304, C*0401, C*0702, DPB1*0301, DPB1*0402, DPB1*1501, DQA1*0102, DQA1*0301, DQA1*0401, DQA1*0501, DQB1*0201, DQB1*0302, DQB1*0402, DQB1*0501, DQB1*0602, DRB1*0301, DRB1*0401, DRB1*0405, DRB1*0801 and DRB1*1501) to see what effects they had on susceptibility to severe infections.

\section{Methods}

Data sources for diagnoses and study sample

Data were obtained by linking Danish population-based registers using the unique personal identification number employed in Denmark since 1968 [16]. The Danish Neonatal Screening Biobank stores dried blood spots taken 4-7 days after birth from nearly all infants born in Denmark after 1981 [16, 17]. Information about infections was obtained from the Danish National Hospital Registry, which, since 1977, contains records of all inpatients treated in Danish non-psychiatric hospitals, and, since 1995, contains information regarding outpatient and emergency room contacts [18]. The Psychiatric Central Research Register covers all psychiatric inpatient facilities since 1969 and outpatient contacts since 1995 [19]. Diagnostic information was based on the 8th Revision of the International Classification of Diseases (ICD-8) [20] from 1977 to 1993, and ICD-10 from 1994 [21]. The individuals in this study are part of the iPSYCH 2012 cohort [22], nested within all individuals in the Danish population born between 1981 and $2005(\mathrm{~N}=1,472,762)$, and which included individuals diagnosed with at least one of: schizophrenia, bipolar disorder or depression (affective disorder), autism spectrum disorder, attention deficit/hyperactivity disorder and anorexia, and individuals included as part of a random population sample. Data pertaining to hospitalization for infections for all individuals in our study were obtained from the National Hospital Registry as described above. The iPSYCH sample has undergone extensive quality control $(\mathrm{QC})$ as described in our previous studies which used imputed HLA alleles or infection diagnoses [12, 14, 15]. Importantly, individuals were removed based on ancestry (if they did not have Danish ancestry, as determined from registry data of family history and genetic principal component analyses) and relatedness (if they were first or second degree relatives of other individuals in the sample prioritizing first iPSYCH cases and then individuals with a higher genotype call rate). Individuals were also removed based on missingness (1\%), abnormal heterozygosity, ambiguous sex (based on genetic markers), or if they were duplicates of other individuals. The first study employing this 
Table 1 Sample sizes of individuals with and without infections requiring hospital contacts among 65,534 individuals (45,889 with psychiatric diagnosis and 19,645 without one)

\begin{tabular}{ll}
\hline Group & Sample size \\
\hline Cases & \\
Any infection & 28,472 \\
Type of infection & \\
Bacterial infections & 11,833 \\
Viral infections & 11,914 \\
Site of infection & \\
CNS infections & 551 \\
Gastrointestinal infections & 7197 \\
Genital infections & 749 \\
Hepatitis infections & 111 \\
Otitis media infections & 5957 \\
Pregnancy-related infections & 661 \\
Respiratory infections & 12,958 \\
Sepsis & 438 \\
Skin infections & 4709 \\
Urological infections & 2106 \\
Other infections & 10,203 \\
Controls & \\
Individuals without any infection & 37,062 \\
\hline
\end{tabular}

QC protocol has more information about the procedures [23]. Before QC, we had genotypes for 78,050 individuals. Following genetic and record-based QC, 65,534 unrelated Danish individuals were retained for downstream analyses (34,705 males and 30,829 females). Data for infections for each individual were up to the end of 2012, and the data for the psychiatric diagnoses were up to the end of 2013. The following infection categories were included in this study: bacterial, viral, central nervous system (CNS), gastrointestinal, genital, hepatitis, otitis, pregnancy-related (this was described somewhat confusingly in previous papers, but it refers to an infection present in the mother, who is in $\mathrm{PSYCH}$, while pregnant with or during delivery of the child, or immediately thereafter), respiratory, sepsis, skin infection, urological or other infections. ICD-8 and ICD-10 codes for these categories can be found in Additional file 1: Table S1. ${ }^{1}$ Individuals without any of these infection diagnoses were defined as controls, and individuals with at least one diagnosis were also defined as cases for the "any infection" phenotype. Sample sizes for all infection categories are shown in Table 1 . There was a small number of people

\footnotetext{
${ }^{1}$ This table corrects a few minor errors in the codes mainly for the bacterial and viral infection categories, as found in previous versions of it, and has more specific (higher resolution) codes for some infections.
}

diagnosed with HIV/AIDS (ICD-8: 07983; ICD-10: B20, $\mathrm{B} 21, \mathrm{~B} 22, \mathrm{~B} 23, \mathrm{~B} 24 ; \mathrm{N}=16$ ). This group was too small for our analyses, and they all had at least one other infection category. They were not excluded as such, but we did not analyze this infection group on its own (they were considered cases for the "any infection" phenotype, and they were excluded from being infection controls).

\section{Imputation of classical HLA alleles}

Samples were genotyped on the Illumina Infinium PsychArray v1.0, as described in the original iPSYCH paper [22]. The dataset used to impute HLA alleles underwent $\mathrm{QC}$ as described in the original $\mathrm{PSYCH}$ paper and a later iPSYCH study [47]. We were supplied with a dataset of 78,050 samples in 23 genotyping waves (this QC also applies to our first HLA study [15]). For the association analyses we used the final list of samples as per the procedure described in the previous section, meaning that samples not passing the QC described under "data sources for diagnoses and study sample" were excluded from downstream analyses; only 65,534 samples were used after the HLA imputation. As described previously [15], single-nucleotide polymorphism data were used to impute HLA types with a four-digit resolution for: HLA-A, HLA-B, HLA-C, HLA-DRB1, HLA-DQA1, $H L A-D Q B 1$ and $H L A-D P B 1$. The HLA imputation was performed with HIBAG [24] v1.3 using a pre-trained four-digit European ancestry model based on the PsychArray-B genotype platform (downloaded from: http:// zhengxwen.github.io/HIBAG/hibag_index.html). The post-imputation QC included a posterior probability inclusion threshold of 0.9 for HLA alleles used in downstream analyses. In total, the following numbers of alleles were imputed for $H L A-A, H L A-B, H L A-C, H L A-D P B 1$, $H L A D Q A 1, H L A-D Q B 1$, and $H L A-D R B 1$, respectively: $31,65,30,21,15,17$, and 43 . After allele and sample QC, the following numbers of alleles remained: $24,42,21$, $15,12,14$, and 27. Our previous paper contains detailed statistical information about the imputed alleles and the quality of the imputation.

\section{Statistical analyses}

As in our association analyses of HLA alleles and psychiatric [15] and autoimmune diseases [13], we employed a two-stage design. Gene-based tests were likelihood ratio tests for two logistic regression models run with the $g l m$ function in R [25] v3.3.1: (i) a full model, which included numeric variables for all HLA alleles for a given gene (with possible values of 0,1 or 2 , denoting the allele count per allele per individual) and covariates for age, age squared (to account for non-linearity with age), sex, the first ten principle components (to account for subtle differences in genetic ancestry) and having a psychiatric 
Table 2 Results of the gene-based likelihood ratio tests ( $p$-values for each test are shown)

\begin{tabular}{llllllll}
\hline Disease/gene & HLA-A & HLA-B & HLA-C & HLA-DPB1 & HLA-DQA1 & HLA-DQB1 & HLA-DRB1 \\
\hline Any infection & 0.1759 & 0.6097 & 0.7975 & 0.6141 & 0.1708 & 0.5422 & 0.4631 \\
Bacterial infection & 0.3187 & 0.1235 & 0.05251 & 0.7455 & 0.7642 & 0.9248 & 0.8715 \\
CNS infection & NA & NA & 0.5737 & $0.01279^{\mathrm{a}}$ & 0.6255 & 0.477 & NA \\
Gastrointestinal infection & 0.5783 & 0.5979 & 0.9051 & 0.03784 & 0.09455 & 0.2796 & 0.4751 \\
Genital infection & 1 & 1 & 0.3614 & 0.1255 & 0.4617 & 0.2426 & NA \\
Hepatitis infection & $\mathrm{NA}$ & $\mathrm{NA}$ & $\mathrm{NA}$ & $\mathrm{NA}$ & 0.07716 & 0.6711 & $\mathrm{NA}$ \\
Other infections & 0.643 & 0.6957 & 0.9214 & 0.7476 & $0.01073^{\mathrm{a}}$ & 0.08866 & 0.4972 \\
Otitis infection & 0.02872 & 0.8145 & 0.6157 & 0.8382 & 0.8545 & 0.8985 & 0.5372 \\
Pregnancy-related infection & 0.6392 & $\mathrm{NA}$ & 0.7479 & 0.4424 & 0.8963 & 0.8691 & $\mathrm{NA}$ \\
Respiratory infection & 0.437 & 0.7647 & 0.2972 & 0.4032 & 0.1343 & 0.09267 & 0.1911 \\
Sepsis & $\mathrm{NA}$ & $\mathrm{NA}$ & 0.4429 & 0.7941 & 0.3766 & $0.003534^{\mathrm{a}}$ & $\mathrm{NA}$ \\
Skin infection & 0.5236 & 0.02606 & 0.2706 & 0.7474 & 0.5656 & 0.6319 & 0.816 \\
Urological infection & 0.6288 & 0.7088 & 0.02561 & 0.3027 & 0.9862 & 0.6622 & 0.6907 \\
Viral infection & 0.2659 & 0.2998 & 0.3384 & 0.3027 & 0.03678 & $0.01402^{\mathrm{a}}$ & 0.0467 \\
\hline
\end{tabular}

NA denotes cases in which the regression/likelihood ratio test failed due to small sample sizes, multicollinearity of the alleles, and/or rare alleles

${ }^{a}$ These associations obtained the lowest q-value (27\%)

diagnosis (ICD-8: 290-315; ICD-10: F00-F99), and (ii) a null model, which included only the covariates (without the allele variables). The $\mathrm{p}$-values are obtained from the chi-squared statistics using the anova function in $\mathrm{R}$. The gene-based tests are omnibus tests which are meant to detect an overall association between an HLA gene and an infection category. It is not possible to make inferences about the effects of individual alleles from these models due to multicollinearity across allele variables. Furthermore, these tests may not work when very rare alleles are present or with small sample sizes/very few observations for cases, due to the influences of these factors on the regression in the full model. However, they can be used as a tool for assessing whether an association signal can be detected, as the full model as a whole may still be valid, as long as one does not try to determine the contributions of the individual independent variables from it [26]. Thus, these tests help focus downstream analyses on specific infection-gene pairs and reduce the overall number of tests. We did not consider infection-gene pairs for further analysis, if the regression/likelihood ratio test for them failed. In sum, these tests offer a tradeoff between a reduction in multiple testing and possibly missing individual allelic associations when the disease is rare or when there are rare occurrences of some alleles (however, the effect of an allele might not be estimated accurately even when tested alone, and the regression model for it might not work, if it has too few occurrences and/or the sample size for the specific regression is too small). Allele-based tests are post hoc tests which are employed to investigate the effects of specific alleles on the infection phenotype. They are logistic regressions of the infection status on the allele count of only one allele and the above covariates. These tests reveal the logadditive effects of specific HLA alleles on disease risk. The reported $\mathrm{p}$-values for these tests are for whether the coefficient [log-odds ratio (OR)] for the allele count is different from zero (Wald $\mathrm{Z}$ test), as implemented in the $\mathrm{glm}$ function in R. False discovery rate (FDR) q-values were calculated using the QVALUE R package with the bootstrap method for all gene-based tests together and for the allele-based tests for each tested disease-gene pair both separately and across all tests, where possible (based on the $\mathrm{p}$-value distributions); otherwise a lambda value of 0 was used [27].

\section{Comparison with autoimmune disease and mental illness and network analysis}

We tested the top alleles associated with a psychiatric disorder or overall autoimmune disease from our previous studies in the context of association with infections. For associations with infections, we visualized the results of all allelic associations which had at least nominally significant $\mathrm{p}$-values $(\mathrm{P} \leq 0.05)$ with at least one infection category or with the "any infection" phenotype. The network was created with Cytoscape [28] v3.8.1. The color of the edges represents the direction of effect (red = risk; blue $=$ protective), and the thickness of the edges corresponds to the absolute value of the estimate $(\ln (\mathrm{OR}))$ from the regression. 


\section{Results}

\section{Associations between HLA alleles and infections}

Table 1 presents all infection categories included in our study and their corresponding sample sizes. In the HLA gene-based tests, 10 tests were nominally significant $(\mathrm{P} \leq 0.05)$, as can be seen in Table 2 . FDR analysis using all p-values obtained a minimum q-value of $27 \%$ for the associations with the four lowest p-values, namely $H L A$ $D Q B 1$ with sepsis infection, $H L A-D Q A 1$ with other infections, $H L A-D P B 1$ with CNS infection and $H L A$ $D Q B 1$ and viral infection. A q-value of $27 \%$ for these four associations suggests a proportion of false positives of $27 \%$ among these i.e. about one of these four associations is expected to be a false positive, although there is no indication as to which one it is. We therefore tested all four with the allele-based tests. The results are presented in Table 3. The allele-based tests highlighted associations between DQB1*0503 and DQB1*0301 with sepsis, DQA1*0301 and DQA1*0103 with other infections and DQB1*0302 and DQB1*0604 with viral infections (with opposite trends in these cases). In terms of their q-values, when each gene-infection pair is tested alone, the associations between DQA1*0301 and other infections, and DQB1*0302 and DQB1*0604 and viral infections obtain $\mathrm{q}<0.05$. When tested together, only the associations between DQA1*0301 and other infections and DQB1*0302 and viral infections obtain $\mathrm{q}<0.05$. The association between DQB1*0503 and sepsis obtained $\mathrm{q}=0.052$ in this case. For certain viral infections, prior studies have shown that zygosity at HLA class II loci might have an effect on infection risk or on the severity of the infection [29-31]. We therefore tested whether there was an association between zygosity at class II loci and having a viral infection. We performed a two-sided Fisher's exact test in $\mathrm{R}$ using a $2 \times 2$ table with counts of individuals (heterozygous/homozygous) and case/control status for viral infections. We did not find any significant associations for $D Q B 1, D R B 1, D P B 1$ or $D Q A 1$ $(\mathrm{OR}=1.006,0.967,1.009,0.994 ; \mathrm{P}=0.863,0.417,0.757$, 0.844 , respectively).

\section{Comparison with associations of HLA alleles with autoimmune disease and mental illness}

Twenty-two alleles were highlighted in our previous studies: 20 alleles for autoimmune disease and 2 alleles for mental illness (see "Background"). As both infection and autoimmune disease are correlated with mental illness, and as the immune system is intrinsically linked to both infection and autoimmune disease, we examined potential associations between the 22 alleles highlighted in our previous studies and all infection categories. We obtained 24 nominally significant associations with at least one infection category (Table 4). The results are also visualized as a network in Fig. 1. Two interesting points to note are the following: (i) while alleles implicated in autoimmune disease are well-connected to infections, alleles implicated in autism spectrum disorder and/or intellectual disability are not connected to infections at all; (ii) regarding alleles connected to both infections and autoimmune disease, with the exception of hepatitis, the effects of those alleles on autoimmune disease are larger than on infections, and the following pattern emerges: for HLA class I alleles (namely alleles of $H L A-C$ ), the trends are discordant between autoimmune disease and infection; they are protective for the former and increase the risk of the latter with similar effect sizes; for HLA class II alleles, the directions of effect are the same across both types of diseases, and they are almost always stronger for autoimmune disease.

\section{Discussion}

This paper reports a comprehensive immunogenetic association study of multiple categories of infections requiring hospitalization. Our sample sizes ranged from 111 cases for hepatitis to 28,472 cases for any severe infection (Table 1), making our study one of the largest genetic studies of infections to date.

We did not detect very strong associations between specific HLA loci and infections at the gene level. This is in sharp contrast to our previous findings with regards to autoimmune disease and, to a lesser extent, psychiatric disorders. This could be due to the intrinsic nature of infections, which are passed horizontally from individual to individual, making the study design less "controlled". In this context it is also important to keep in mind the relatively low heritability for overall infection observed in our previous study using this cohort [14]. Alternatively, this could be the result of a small sample size for some infection categories combined with the allele frequencies of some rare alleles, or it could be due to the degree of heterogeneity of the infection phenotypes. For some viral infections, especially hepatitis B and C, the zygosity at specific HLA class II loci might also be important [2931 , but in some cases it pertained mostly to the severity of the infection. We did not observe this effect for class II loci in our study. With regards to differences in the results between our study and previous studies, they could also have arisen due to differences in the resolution of HLA typing, differences in the definitions of the phenotypes and/or population effects, and it should be noted that many of the old studies had very small samples [8]. Our results could also reflect true small effects. In this context it is important to mention a study by Tian et al. from 2017, which reported highly significant associations between HLA alleles and several specific infections [32]. However, this study examined specific common 
Table 3 Results of the allele-based tests for top associations from the gene-based tests (only results for regressions that worked are shown; ORs were calculated before the truncation of some of the decimal places from the estimates)

\begin{tabular}{|c|c|c|c|c|c|}
\hline Infection category & Allele & Estimate $(\ln (O R))$ & $\begin{array}{l}\text { Std. error of the } \\
\text { estimate }\end{array}$ & OR (odds ratio) & $p$-value \\
\hline Sepsis & DQB1*0503 & 0.559104 & 0.203687 & 1.749105 & 0.006053 \\
\hline Sepsis & DQB1*0301 & -0.24618 & 0.105892 & 0.78178 & 0.020081 \\
\hline Sepsis & $\mathrm{DQB1}{ }^{* 0602}$ & 0.184527 & 0.095393 & 1.20265 & 0.053066 \\
\hline Sepsis & $\mathrm{DQB1}{ }^{* 0502}$ & -1.25217 & 0.710498 & 0.285883 & 0.078004 \\
\hline Sepsis & DQB1*0501 & 0.172764 & 0.10667 & 1.188585 & 0.105317 \\
\hline Sepsis & $\mathrm{DQB} 1 * 0303$ & 0.212767 & 0.156171 & 1.237096 & 0.173072 \\
\hline Sepsis & $\mathrm{DQB1}{ }^{* 0302}$ & -0.14869 & 0.112826 & 0.861833 & 0.187535 \\
\hline Sepsis & DQB1*0603 & -0.20829 & 0.159683 & 0.811969 & 0.192091 \\
\hline Sepsis & DQB1*0609 & -1.14838 & 1.003663 & 0.317152 & 0.252547 \\
\hline Sepsis & $\mathrm{DQB1}{ }^{* 0402}$ & -0.23573 & 0.212697 & 0.789997 & 0.267743 \\
\hline Sepsis & DQB1*0201 & 0.104055 & 0.126681 & 1.109661 & 0.411423 \\
\hline Sepsis & DQB1*0604 & -0.11078 & 0.161356 & 0.895133 & 0.492351 \\
\hline Sepsis & DQB1*0202 & 0.086373 & 0.132958 & 1.090213 & 0.515934 \\
\hline Sepsis & $\mathrm{DQB1}{ }^{* 06} 01$ & -0.16911 & 0.506018 & 0.844415 & 0.738229 \\
\hline Other infections & DQA $1 * 0301$ & 0.094638 & 0.026576 & 1.099261 & 0.000369 \\
\hline Other infections & DQA1*0103 & -0.0716 & 0.03371 & 0.930902 & 0.033665 \\
\hline Other infections & DQA1*0601 & -0.46193 & 0.263865 & 0.630068 & 0.080012 \\
\hline Other infections & DQA1*0102 & -0.028 & 0.020206 & 0.972385 & 0.165775 \\
\hline Other infections & DQA1*0401 & 0.051297 & 0.045862 & 1.052635 & 0.263356 \\
\hline Other infections & DQA $1 * 0303$ & 0.040546 & 0.037877 & 1.041379 & 0.284414 \\
\hline Other infections & DQA 1*0201 & -0.02777 & 0.027843 & 0.97261 & 0.318535 \\
\hline Other infections & DQA $1 * 0101$ & -0.02144 & 0.028011 & 0.978789 & 0.444044 \\
\hline Other infections & DQA 1*0505 & 0.014933 & 0.028517 & 1.015045 & 0.600533 \\
\hline Other infections & DQA 1*0104 & 0.035278 & 0.088494 & 1.035908 & 0.690147 \\
\hline Other infections & DQA 1*0302 & -0.04039 & 0.117462 & 0.960416 & 0.730961 \\
\hline Other infections & DQA1*0501 & 0.000725 & 0.030631 & 1.000725 & 0.981128 \\
\hline CNS infection & DPB1*1101 & -0.77846 & 0.452205 & 0.459111 & 0.085163 \\
\hline CNS infection & DPB1*1401 & 1.210008 & 0.727933 & 3.353512 & 0.096462 \\
\hline CNS infection & DPB1*1001 & -0.76275 & 0.504907 & 0.46638 & 0.13087 \\
\hline CNS infection & DPB1*1301 & -0.66143 & 0.451917 & 0.516111 & 0.143299 \\
\hline CNS infection & DPB1*0201 & -0.16001 & 0.129761 & 0.852137 & 0.21754 \\
\hline CNS infection & DPB1*0101 & 0.179176 & 0.14896 & 1.196231 & 0.229037 \\
\hline CNS infection & DPB1*1601 & -0.61661 & 0.5786 & 0.539769 & 0.286559 \\
\hline CNS infection & DPB1*1501 & -0.6103 & 0.581432 & 0.54319 & 0.293882 \\
\hline CNS infection & DPB $1 * 0301$ & 0.106403 & 0.113766 & 1.11227 & 0.349642 \\
\hline CNS infection & DPB1*0402 & 0.096617 & 0.112958 & 1.101438 & 0.392365 \\
\hline CNS infection & DPB $1 * 0401$ & 0.053141 & 0.074281 & 1.054578 & 0.474359 \\
\hline CNS infection & DPB1*1901 & -0.25458 & 0.451412 & 0.775241 & 0.572777 \\
\hline CNS infection & DPB $1 * 0501$ & 0.06585 & 0.210093 & 1.068066 & 0.753953 \\
\hline CNS infection & DPB1*1701 & 0.025801 & 0.338575 & 1.026136 & 0.939257 \\
\hline CNS infection & $\mathrm{DPB} 1^{*} 10401^{\mathrm{a}}$ & -13.2288 & 210.2299 & $1.8 \mathrm{E}-06$ & 0.949826 \\
\hline Viral infection & $\mathrm{DQB1}{ }^{* 0302}$ & 0.06831 & 0.022884 & 1.070697 & 0.002835 \\
\hline Viral infection & DQB1*0604 & -0.08484 & 0.034645 & 0.918659 & 0.014332 \\
\hline Viral infection & DQB1*0609 & -0.24632 & 0.13764 & 0.78167 & 0.073516 \\
\hline Viral infection & $\mathrm{DQB} 1 * 0201$ & 0.046721 & 0.027877 & 1.04783 & 0.093743 \\
\hline Viral infection & $\mathrm{DQB1}{ }^{* 0603}$ & -0.04453 & 0.032445 & 0.956449 & 0.169931 \\
\hline Viral infection & $\mathrm{DQB1}{ }^{* 0303}$ & -0.04964 & 0.038459 & 0.951569 & 0.196766 \\
\hline Viral infection & DQB1*0601 & -0.12332 & 0.107941 & 0.88398 & 0.253254 \\
\hline
\end{tabular}


Table 3 (continued)

\begin{tabular}{llcccc}
\hline Infection category & Allele & Estimate $(\ln (\mathbf{O R}))$ & $\begin{array}{l}\text { Std. error of the } \\
\text { estimate }\end{array}$ & OR (odds ratio) & p-value \\
\hline Viral infection & DQB1*0503 & 0.058851 & 0.057194 & 1.060617 & 0.303494 \\
Viral infection & DQB1*0202 & -0.0249 & 0.030592 & 0.97541 & 0.41574 \\
Viral infection & DQB1*0301 & 0.016236 & 0.021299 & 1.016369 & 0.445881 \\
Viral infection & DQB1*0602 & -0.01546 & 0.022136 & 0.984661 & 0.484981 \\
Viral infection & DQB1*0402 & -0.02045 & 0.04206 & 0.979754 & 0.62675 \\
Viral infection & DQB1*0502 & 0.005057 & 0.085364 & 1.00507 & 0.95276 \\
Viral infection & DQB1*0501 & 0.000455 & 0.024834 & 1.000455 & 0.985382
\end{tabular}

${ }^{a}$ The regression analysis for this allele resulted in a large standard error of its estimate due to its low frequency and therefore its effect cannot be determined accurately

Table 4 Associations between infections and alleles implicated in autoimmune disease or mental illness from our previous studies (only associations with $\mathrm{P} \leq 0.05$ are shown; ORs were calculated before the truncation of some of the decimal places from the

\begin{tabular}{|c|c|c|c|c|c|}
\hline Astínates) & Estimate $(\ln (\mathrm{OR}))$ & $\begin{array}{l}\text { Std. error of the } \\
\text { estimate }\end{array}$ & OR (odds ratio) & $p$-value & Infection category \\
\hline $\mathrm{DQA} 1 * 0102$ & -0.0292 & 0.014231 & 0.971221 & 0.040168 & Any infection \\
\hline $\mathrm{DQA} 1 * 0301$ & 0.052435 & 0.019077 & 1.053834 & 0.005984 & Any infection \\
\hline $\mathrm{DQB1}{ }^{* 0302}$ & 0.04346 & 0.017379 & 1.044418 & 0.012395 & Any infection \\
\hline $\mathrm{DRB} 1 * 0401$ & 0.051723 & 0.023683 & 1.053084 & 0.028967 & Any infection \\
\hline $\mathrm{DQA1}{ }^{*} 0301$ & 0.08244 & 0.030735 & 1.085933 & 0.007311 & Gastrointestinal infection \\
\hline $\mathrm{DQB1}{ }^{*} 0302$ & 0.074499 & 0.028013 & 1.077345 & 0.007826 & Gastrointestinal infection \\
\hline $\mathrm{DQA} 1 * 0301$ & 0.168838 & 0.084957 & 1.183928 & 0.046885 & Genital infection \\
\hline $\mathrm{DRB} 1 * 0401$ & 0.230091 & 0.103525 & 1.258714 & 0.026246 & Genital infection \\
\hline $\mathrm{DRB} 1 * 0801$ & 0.806151 & 0.353065 & 2.239273 & 0.022413 & Hepatitis infection \\
\hline $\mathrm{DQA} 1{ }^{*} 0301$ & 0.094638 & 0.026576 & 1.099261 & 0.000369 & Other infections \\
\hline $\mathrm{DQB1}{ }^{*} 0302$ & 0.077648 & 0.024273 & 1.080742 & 0.001379 & Other infections \\
\hline $\mathrm{DRB} 1 * 0401$ & 0.065745 & 0.033446 & 1.067954 & 0.049336 & Other infections \\
\hline$C^{*} 0401$ & 0.277345 & 0.101347 & 1.319621 & 0.006208 & Pregnancy-related infection \\
\hline $\mathrm{DQA} 1 * 0102$ & -0.0369 & 0.018438 & 0.963772 & 0.045357 & Respiratory infection \\
\hline $\mathrm{DQA1}{ }^{*} 0301$ & 0.074712 & 0.024401 & 1.077574 & 0.0022 & Respiratory infection \\
\hline $\mathrm{DQB1}{ }^{*} 0302$ & 0.063564 & 0.022285 & 1.065628 & 0.004341 & Respiratory infection \\
\hline DRB 1*0401 & 0.067727 & 0.030469 & 1.070073 & 0.026227 & Respiratory infection \\
\hline$C^{*} 0702$ & 0.182894 & 0.089832 & 1.200687 & 0.041754 & Sepsis \\
\hline DQA $1 * 0301$ & 0.081349 & 0.036639 & 1.084749 & 0.026398 & Skin infection \\
\hline$C^{*} 0401$ & 0.193844 & 0.057718 & 1.213907 & 0.000784 & Urological infection \\
\hline $\mathrm{DQA} 1 * 0102$ & -0.03836 & 0.019028 & 0.962365 & 0.0438 & Viral infection \\
\hline $\mathrm{DQA1}{ }^{*} 0301$ & 0.066253 & 0.025166 & 1.068497 & 0.008472 & Viral infection \\
\hline $\mathrm{DQB1}{ }^{*} 0302$ & 0.06831 & 0.022884 & 1.070697 & 0.002835 & Viral infection \\
\hline $\mathrm{DRB} 1{ }^{*} 0401$ & 0.089667 & 0.031349 & 1.09381 & 0.004232 & Viral infection \\
\hline
\end{tabular}

infections, whereas our study examined severe infections requiring hospitalization, in broader categories of infection type; this could also suggest different effects to risk of infection and severity of infection (although our current study cannot address this possibility). Moreover, the sample size of the 2017 study was over 200,000, thus allowing the detection of smaller effects. Most of the associations the authors report have, in fact, small to moderate effect sizes, albeit highly significant ones. Our own analyses nonetheless highlighted several classical HLA alleles. Several of these have been implicated in past studies of infections. A haplotype with DQB1*0503, which in our study was a risk allele for sepsis, had also been associated with severe systemic disease (SSD) in 


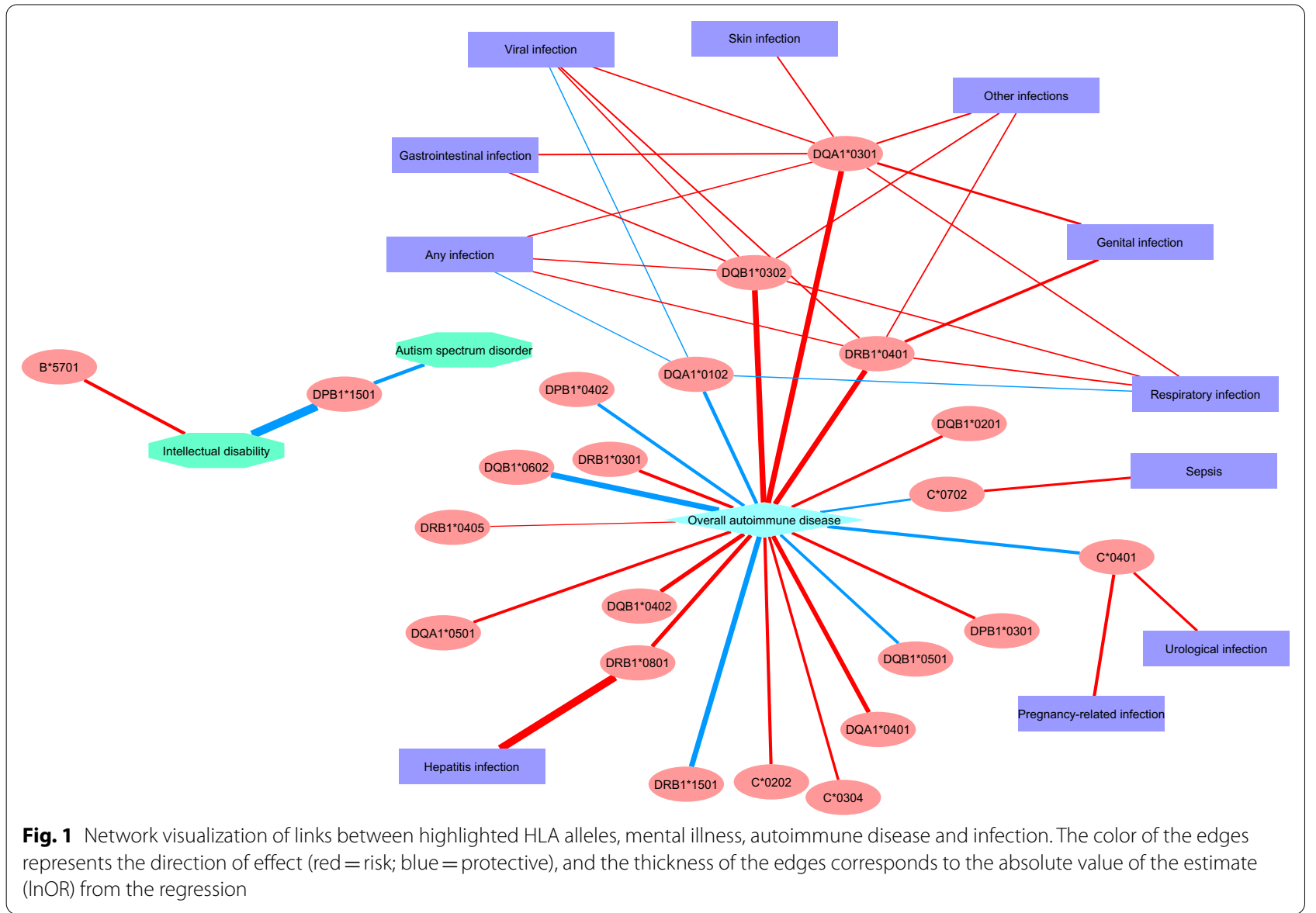

the absence of necrotizing fasciitis (NF) in the context of severe, invasive, group A streptococcal infection (GAS) [33]. In the same study, DQB1*0301, which reduced the risk of sepsis in our study, was associated with NF in the absence of SSD. While this study suggested interactions between these alleles, SSD and NF (in the context of GAS), our results demonstrate that what could be a risk allele for one complication could be protective for another; however, this is only speculative, as we did not investigate specific complications of infection. Nonetheless, as these two complications can be seen as either an over-reaction (SSD) or insufficient response (NF) of the immune system, these opposite effects do make some biological sense. DQA1"0301 (risk) and DQA1"0103 (protective) were associated with the "other infections" category. This infection category encompasses potentially very different infection diagnoses by definition, and so it may be hard to draw conclusions about these associations. However, these alleles were highlighted in past studies of gastrointestinal diseases or liver diseases: DQA1"0301 was reported as a risk factor for Helicobacter pylori infection [34]. Conversely, DQA1*03 was found to have a protective effect on chronic hepatitis $\mathrm{C}$ infection
[35]. DQA1*0103, which was protective in our study, was found to be associated with spontaneous recovery from hepatitis B infection [36]. Lastly, DQB1*0302 (risk) and DQB1*0604 (protective) showed association with viral infections. Like DQA1*03, DQB1*0302 was found to reduce risk of chronic hepatitis $\mathrm{C}$ infection in the above study [35]. A haplotype with DQB1*0604 was associated with low hepatitis activity in the context of chronic hepatitis C infections [37].

In the second part of our study, we examined whether alleles previously associated with psychiatric disorders or autoimmune disease from our previous studies showed association with infections. As can be seen in Fig. 1, there were no common alleles to both psychiatric disorders and infections. In contrast, several of the alleles significantly associated with autoimmune disease showed some association with infections. With one notable exception, when an allele was associated in the same direction with both autoimmune disease and an infection, its effect was larger on the former. For $H L A-C$ alleles showing association with both disease classes, the direction of association was discordant between autoimmune disease (protective) and infections (risk). The latter result could potentially 
be explained by considering a mechanism whereby some $H L A-C$ alleles lead to low immune reactivity to specific ligands, thus lowering the risk of autoimmune disease but increasing the risk of infection, if there is some e.g. structural connection between an infectious antigen and a self-antigen the HLA molecule can bind. Some alleles are also known to have lower surface expression and other alternative expression patterns in general. A mechanism for a related scenario, whereby the binding capabilities of specific HLA molecules to self-antigens which resemble microbial peptides can lead to autoimmune disease, has been proposed, but there is conflicting evidence in this regard, and, in that scenario, the HLA molecule in question also showed extracellular binding capabilities [38-41]. Interestingly, a recent study reported cross-reactivity between an enterococcal bacteriophage peptide and tumor antigens binding to MHC class I molecules [42]. The associations with concordant trends across infections and autoimmune disease are conceptually harder to speculate about, perhaps, but it should be noted that, with the exception of DRB1*0801 and hepatitis, the effect sizes of the associations with infections in those cases are smaller, with the average absolute value of the effect size (regression coefficient) being $\sim 0.08$ (compared to $\sim 0.47$ for autoimmune disease). As noted above, one exception to this is the association between DRB1*0801 and hepatitis, which is stronger than the former's association with autoimmune disease, and in the same direction. This allele, however, is consistently reported as associated with an autoimmune disease of the liver, namely, primary biliary cirrhosis (PBC) $[43,44]$. Moreover, a diagnosis of $\mathrm{PBC}$ may be delayed in individuals with viral hepatitis [45], and a differential diagnosis between $\mathrm{PBC}$ and viral hepatitis can be difficult due to some PBC pathophysiology which can mimic chronic hepatitis, especially hepatitis $C$ [46]. Since we do not have access to this kind of data for the individuals in our study, we cannot rule out that these factors could have potentially influenced the diagnosis and hence the observed association. Hepatitis was also the smallest infection category in our study in terms of sample size, which could suggest that the effect size for its association is inflated.

\section{Conclusions}

In conclusion, while our study confirmed some previously reported associations with classical HLA alleles, the overall picture suggests that the effects of HLA alleles on susceptibility to severe infections are not large, especially when compared with their effects on risk of autoimmune disease. Some alleles, notably two $H L A-C$ alleles, had discordant effects on susceptibility to infection and autoimmune disease, in line with some hypotheses regarding the origins of some autoimmune diseases. Unlike in the case of autoimmune disease, classical HLA alleles might not play a large role in the etiology of severe infections, although there is some evidence for their involvement therein.

\section{Abbreviations \\ CNS: Central nervous system; FDR: False discovery rate; GAS: Group A streptococcal infection; HLA: Human leukocyte antigen; ICD: International Classification of Diseases; MHC: Human major histocompatibility complex; NF: Necrotizing fasciitis; PBC: Primary biliary cirrhosis; QC: Quality control; SSD: Severe systemic disease.}

\section{Supplementary Information}

The online version contains supplementary material available at https://doi. org/10.1186/s12967-021-02888-1.

Additional file 1: Table S1. ICD-8 and ICD-10 codes for site and type of infection.

\section{Acknowledgements}

This research has been conducted using the Danish National Biobank resource supported by the Novo Nordisk Foundation. The iPSYCH data were stored and analyzed at the Computerome HPC Facility (http://www.computerome. dtu.dk/), with the support of the HPC team led by Dr. Ali Syed. We thank Allan Timmermann for creating the original infection dataset and for his clarifications of the ICD codes used in this study. We thank Georgios Athanasiadis for checking the nationwide register data for us during the correction of Additional file 1: Table S1. The iPSYCH Consortium was established through the work of six principal investigators in Denmark: from Aarhus University: Preben B. Mortensen, Ole Mors, Anders D. Børglum; from the University of Copenhagen, Mental Health Services of the Capital Region of Denmark and/or Statens Serum Institut: Thomas Werge, Merete Nordentoft, David M. Hougaard.

\section{Authors' contributions}

MEB and RN conceived the study. RN designed the study, performed the statistical genetic analyses, interpreted the results, wrote the manuscript; MEB supervised the analyses, contributed to the interpretation of the results and the drafting of the manuscript; RLA and SR performed the imputation and QC of HLA alleles. TW is the principal investigator from iPSYCH who oversaw the study; WKT contributed to the design of the statistical analyses. All authors have read and approved the manuscript.

\section{Funding}

This study was funded by The Lundbeck Foundation, Denmark (Grant Numbers R268-2016-3925, R102-A91 18 and R155-2014-1724), the Independent Research Fund Denmark (Grant Number 7025-00078B), the Mental Health Services Capital Region of Denmark, University of Copenhagen, Aarhus University and the University Hospital in Aarhus. The genotyping of the iPSYCH samples was supported by grants from the Lundbeck Foundation, the Stanley Foundation, the Simons Foundation (SFARI 311789), and NIMH (5U01MH094432-02). SR was supported by a Grant from the Novo Nordisk Foundation (NNF14CC0001).

\section{Availability of data and materials}

iPSYCH data are stored in a national HPC facility in Denmark. The iPSYCH initiative is committed to providing access to these data to the scientific community, in accordance with Danish law. Researchers may be granted access upon request to the iPSYCH management. 


\section{Declarations}

Ethics approval and consent to participate

The Danish Scientific Ethics Committee approved this study (ESDH 1-10-72287-12). The following institutions also approved the study: the Danish Health Data Authority, the Danish data protection agency and the Danish Neonatal Screening Biobank Steering. All personal information from the registers is anonymized when used for research purposes, according to Danish legislation; informed consent from participants was not required.

\section{Consent for publication}

Not applicable.

\section{Competing interests}

All researchers had full independence from the funders. The authors report no biomedical financial interests or potential conflicts of interest. TW states that he has acted as a lecturer and scientific counselor to H. Lundbeck A/S.

\section{Author details}

${ }^{1}$ Institute of Biological Psychiatry, Mental Health Centre Sct. Hans, Mental Health Services Copenhagen, Roskilde, Denmark. ${ }^{2}$ PSSYCH, The Lundbeck Foundation Initiative for Integrative Psychiatric Research, Aarhus, Denmark. ${ }^{3}$ CORE - Copenhagen Research Centre for Mental Health, Mental Health Centre Copenhagen, Copenhagen University Hospital, Copenhagen, Denmark. ${ }^{4}$ Novo Nordisk Foundation Center for Protein Research, Faculty of Health and Medical Sciences, University of Copenhagen, Copenhagen, Denmark. ${ }^{5}$ Division of Biostatistics, Herbert Wertheim School of Public Health and Human Longevity Science, University of California, San Diego, CA, USA. ${ }^{6}$ Department of Clinical Medicine, Faculty of Health and Medical Sciences, University of Copenhagen, Copenhagen, Denmark. ${ }^{7}$ Department of Immunology and Microbiology, Faculty of Health and Medical Sciences, University of Copenhagen, Copenhagen, Denmark.

Received: 21 January 2021 Accepted: 17 May 2021

Published online: 31 May 2021

\section{References}

1. World Health Organization. The global burden of disease: 2004 update. Geneva; 2004

2. Liu L, Oza S, Hogan D, Chu Y, Perin J, Zhu J, et al. Global, regional, and national causes of under-5 mortality in 2000-15: an updated systematic analysis with implications for the sustainable development goals. The Lancet. 2016;388(10063):3027-35.

3. Teh CL, Wan SA, Ling GR. Severe infections in systemic lupus erythematosus: disease pattern and predictors of infection-related mortality. Clin Rheumatol. 2018;37(8):2081-6 (Epub 2018/04/19).

4. de Castro Rodrigues Ferreira F, Cristelli MP, Paula MI, Proença H, Felipe CR, Tedesco-Silva H, et al. Infectious complications as the leading cause of death after kidney transplantation: analysis of more than 10,000 transplants from a single center. J Nephrol. 2017:30(4):601-6.

5. Ovsyannikova IG, Haralambieva IH, Crooke SN, Poland GA, Kennedy RB. The role of host genetics in the immune response to SARS-CoV-2 and COVID-19 susceptibility and severity. Immunol Rev. 2020;296(1):205-19 (Epub 2020/07/14)

6. Choo SY. The HLA system: genetics, immunology, clinical testing, and clinical implications. Yonsei Med J. 2007:48(1):11-23 (Epub 2007/02/28).

7. Vandiedonck C, Knight JC. The human Major histocompatibility complex as a paradigm in genomics research. Brief Funct Genomic Proteomic. 2009;8(5):379-94 (Epub 2009/05/27)

8. Blackwell JM, Jamieson SE, Burgner D. HLA and infectious diseases. Clin Microbiol Rev. 2009;22(2):370-85 (Table of Contents. Epub 2009/04/16)

9. Sanchez-Mazas A. A review of HLA allele and SNP associations with highly prevalent infectious diseases in human populations. Swiss Med Wkly. 2020;150:w20214 (Epub 2020/04/17).

10. Gough SC, Simmonds MJ. The HLA region and autoimmune disease: associations and mechanisms of action. Curr Genomics. 2007;8(7):453-65 (Epub 2007/11/01)
11. Wright P, Nimgaonkar VL, Donaldson PT, Murray RM. Schizophrenia and HLA: a review. Schizophr Res. 2001;47(1):1-12 (Epub 2001/02/13).

12. Nudel R, Appadurai V, Schork AJ, Buil A, Bybjerg-Grauholm J, Borglum AD, et al. A large population-based investigation into the genetics of susceptibility to gastrointestinal infections and the link between gastrointestinal infections and mental illness. Hum Genet. 2020;139(5):593-604 (Epub 2020/03/11)

13. Liu X, Nudel R, Thompson WK, Appadurai V, Schork AJ, Buil A, et al. Genetic factors underlying the bidirectional relationship between autoimmune and mental disorders_-findings from a Danish populationbased study. Brain Behavior Immunity. 2020 (Epub 2020/06/14).

14. Nudel R, Wang Y, Appadurai V, Schork AJ, Buil A, Agerbo E, et al. A largescale genomic investigation of susceptibility to infection and its association with mental disorders in the Danish population. Transl Psychiatry. 2019;9(1):283 (Epub 2019/11/13).

15. Nudel R, Benros ME, Krebs MD, Allesoe RL, Lemvigh CK, BybjergGrauholm J et al. Immunity and mental illness: findings from a Danish population-based immunogenetic study of seven psychiatric and neurodevelopmental disorders. Eur J Human Genetics EJHG. 2019 (Epub 2019/04/13).

16. Pedersen CB. The Danish civil registration system. Scand J Public Health. 2011;39(7 Suppl):22-5 (Epub 2011/08/04).

17. Norgaard-Pedersen B, Hougaard DM. Storage policies and use of the Danish Newborn Screening Biobank. J Inherit Metab Dis. 2007;30(4):530-6 (Epub 2007/07/17).

18. Andersen TF, Madsen M, Jorgensen J, Mellemkjoer L, Olsen JH. The Danish National Hospital Register. A valuable source of data for modern health sciences. Danish Med Bull. 1999;46(3):263-8 (Epub 1999/07/28).

19. Mors O, Perto GP, Mortensen PB. The Danish psychiatric central research register. Scand J Public Health. 2011;39(7 Suppl):54-7 (Epub 2011/08/04)

20. World Health Organization. Klassifikation Af Sygdomme; Udvidet DanskLatinsk Udgave Af Verdenssundhedsorganisationens Internationale Klassifikation Af Sygdomme. 8 Revision, 1965 [Classification of Diseases: Extended Danish-Latin Version of the World Health Organization International Classification of Diseases. Copenhagen 1971.

21. World Health Organization. WHO ICD-10: Psykiske Lidelser Og Adfærdsmæssige Forstyrelser. Klassifikation Og Diagnosekriterier [WHO ICD-10: Mental and Behavioural Disorders. Classification and Diagnostic Criteria]. Copenhagen 1994

22. Pedersen CB, Bybjerg-Grauholm J, Pedersen MG, Grove J, Agerbo E, Baekvad-Hansen M, et al. The iPSYCH2012 case-cohort sample: new directions for unravelling genetic and environmental architectures of severe mental disorders. Mol Psychiatry. 2017;23:6-14 (Epub 2017/09/20).

23. Schork AJ, Won H, Appadurai V, Nudel R, Gandal M, Delaneau O, et al. A genome-wide association study of shared risk across psychiatric disorders implicates gene regulation during fetal neurodevelopment. Nat Neurosci. 2019;22(3):353-61 (Epub 2019/01/30).

24. Zheng X, Shen J, Cox C, Wakefield JC, Ehm MG, Nelson MR, et al. HIBAGHLA genotype imputation with attribute bagging. Pharmacogenomics J. 2014;14(2):192-200 (Epub 2013/05/29).

25. R Core Team. R: a language and environment for statistical computing. Vienna, Austria: R Foundation for Statistical Computing: 2014.

26. Andersen PK, Skovgaard LT. Regression with linear predictors. New York: Springer; 2010

27. Storey JD. A direct approach to false discovery rates. J R Stat Soc Ser B (Stat Methodol). 2002;64(3):479-98.

28. Shannon P, Markiel A, Ozier O, Baliga NS, Wang JT, Ramage D, et al. Cytoscape: a software environment for integrated models of biomolecular interaction networks. Genome Res. 2003;13(11):2498-504 (Epub 2003/11/05)

29. Thursz MR, Thomas HC, Greenwood BM, Hill AV. Heterozygote advantage for HLA class-Il type in hepatitis B virus infection. Nat Genet. 1997:17(1):11-2 (Epub 1997/09/01).

30. Hraber P, Kuiken C, Yusim K. Evidence for human leukocyte antigen heterozygote advantage against hepatitis $C$ virus infection. Hepatology. 2007;46(6):1713-21 (Epub 2007/10/16)

31. Lipsitch M, Bergstrom CT, Antia R. Effect of human leukocyte antigen heterozygosity on infectious disease outcome: the need for allele-specific measures. BMC Med Genet. 2003;4:2 (Epub 2003/01/25). 
32. Tian C, Hromatka BS, Kiefer AK, Eriksson N, Noble SM, Tung JY, et al. Genome-wide association and HLA region fine-mapping studies identify susceptibility loci for multiple common infections. Nat Commun. 2017;8(1):599 (Epub 2017/09/21).

33. Kotb M, Norrby-Teglund A, McGeer A, El-Sherbini H, Dorak MT, Khurshid $A$, et al. An immunogenetic and molecular basis for differences in outcomes of invasive group A streptococcal infections. Nat Med. 2002;8(12):1398-404 (Epub 2002/11/19).

34. Azuma T, Konishi J, Tanaka Y, Hirai M, Ito S, Kato T, et al. Contribution of HLA-DQA gene to host's response against Helicobacter pylori. Lancet. 1994;343(8896):542-3 (Epub 1994/02/26)

35. Tibbs C, Donaldson P, Underhill J, Thomson L, Manabe K, Williams R. Evidence that the HLA DQA $1 * 03$ allele confers protection from chronic HCV-infection in Northern European Caucasoids. Hepatology. 1996;24(6):1342-5 (Epub 1996/12/01).

36. Karra VK, Chowdhury SJ, Ruttala R, Gumma PK, Polipalli SK, Chakravarti A, et al. HLA-DQA1 \& DQB1 variants associated with hepatitis B virus-related chronic hepatitis, cirrhosis \& hepatocellular carcinoma. Indian J Med Res. 2018;147(6):573-80 (Epub 2018/09/01).

37. Kuzushita N, Hayashi N, Moribe T, Katayama K, Kanto T, Nakatani S, et al. Influence of HLA haplotypes on the clinical courses of individuals infected with hepatitis C virus. Hepatology. 1998;27(1):240-4 (Epub 1998/01/13)

38. Bowness P. Hla-B27. Annu Rev Immunol. 2015;33:29-48 (Epub 2015/04/12

39. Bodis $G$, Toth $\vee$, Schwarting A. Role of human leukocyte antigens (HLA) in autoimmune diseases. Rheumatol Ther. 2018;5(1):5-20 (Epub 2018/03/09).

40. Benjamin R, Parham P. Guilt by association: HLA-B27 and ankylosing spondylitis. Immunol Today. 1990;11(4):137-42 (Epub 1990/04/01).

41. Benjamin RJ, Madrigal JA, Parham P. Peptide binding to empty HLA-B27 molecules of viable human cells. Nature. 1991;351(6321):74-7 (Epub 1991/05/02).

42. Fluckiger A, Daillere R, Sassi M, Sixt BS, Liu P, Loos F, et al. Cross-reactivity between tumor MHC class I-restricted antigens and an enterococcal bacteriophage. Science. 2020;369(6506):936-42 (Epub 2020/08/21).

43. Donaldson PT, Baragiotta A, Heneghan MA, Floreani A, Venturi C, Underhill JA, et al. HLA class II alleles, genotypes, haplotypes, and amino acids in primary biliary cirrhosis: a large-scale study. Hepatology. 2006;44(3):66774 (Epub 2006/08/31).

44. Qin B, Wang J, Chen J, Liang Y, Yang Z, Zhong R. Association of human leukocyte antigen class II with susceptibility to primary biliary cirrhosis: a systematic review and meta-analysis. PLoS ONE. 2013;8(11):e79580 (Epub 2013/11/23)

45. Rigopoulou El, Zachou K, Gatselis NK, Papadamou G, Koukoulis GK, Dalekos GN. Primary biliary cirrhosis in HBV and HCV patients: clinical characteristics and outcome. World J Hepatol. 2013;5(10):577-83 (Epub 2013/11/02).

46. Washington MK. Autoimmune liver disease: overlap and outliers. Modern Pathol Off J US Canad Acad Pathol. 2007;20(Suppl 1):S15-30.

47. Grove J, Ripke S, Als TD, Mattheisen M, Walters RK, Won H, Pallesen J, Agerbo E, Andreassen OA, Anney R, Awashti S, Belliveau R, Bettella F, Buxbaum JD, Bybjerg-Grauholm J, Bækvad-Hansen M, Cerrato F, Chambert K, Christensen JH, Churchhouse C, Dellenvall K, Demontis D, De Rubeis S, Devlin B, Djurovic S, Dumont AL, Goldstein Jl, Hansen CS, Engel Hauberg M, Hollegaard MV, Hope S, Howrigan DP, Huang H, Hultman CM, Klei L, Maller J, Martin J, Martin AR, Moran JL, Nyegaard M, Nærland T, Palmer DS, Palotie A, Bøcker Pedersen C, Giørtz Pedersen M, dPoterba T, Buchhave Poulsen J, St Pourcain B, Qvist P, Rehnström K, Reichenberg A, Reichert J, Robinson EB, Roeder K, Roussos P, Saemundsen E, Sandin S, Kyle Satterstrom F, Davey Smith G, Stefansson H, Steinberg S, Stevens CR, Sullivan PF, Turley P, Bragi Walters G, Xu X, Autism Spectrum Disorder Working Group of the Psychiatric Genomics Consortium, BUPGEN, Major Depressive Disorder Working Group of the Psychiatric Genomics Consortium, 23andMe Research Team, Stefansson K, Geschwind DH, Nordentoft M, Hougaard DM, Werge T, Mors O, Mortensen PB, Neale BM, Daly MJ, Børglum AD (2019) Identification of common genetic risk variants for autism spectrum disorder. Nature Genetics 51(3):431-444. https://doi.org/ 10.1038/s41588-019-0344-8

\section{Publisher's Note}

Springer Nature remains neutral with regard to jurisdictional claims in published maps and institutional affiliations.
Ready to submit your research? Choose BMC and benefit from:

- fast, convenient online submission

- thorough peer review by experienced researchers in your field

- rapid publication on acceptance

- support for research data, including large and complex data types

- gold Open Access which fosters wider collaboration and increased citations

- maximum visibility for your research: over 100M website views per year

At BMC, research is always in progress.

Learn more biomedcentral.com/submissions 